\title{
V.-RESEARCH.
}

\section{ON THE TEMPERATURE-SENSE}

\section{By Henry Herbert Donaldoon,}

Psyehophysical Laboratory, Johns Hopkins University, Baltimore.

\section{Historical.}

IN the course of an investigation andertaken with. Prof. G. Stanley Hall and under his direction, it was incidentally observed that the sensation of cold was felt only at definite spots on the skin.

The fact was noticed in this way: The sensations of motion as derived from the skin were being studied by means of a metal point which was slowly drawn over the surface. When the motion of this point, which was controlled by a suitable apparatus, was very slow, it often happened that it seemed to stand still for a time or even be lost, when suddenly a sharp sensation of cold, distinctly localised, would recall its presence and position.

This occurred so often that I find in my protocol for April 18th, 1884, the note: "Point always felt as cold". This fact arrested my attention, and in connexion with the other work I made several maps of these cold-spots on different parts of the body. When the experiments had reached this point, an important paper by Magnus Blix (1) ${ }^{1}$ came into my hands.

This investigator started from the law of the specific energies of nerves, and took up the study of the dermal sensations to determine, if possible, how well-founded was the contradiction which they apparently offered to this law. He employed unipolar electrical stimulation, using a pin for his small electrode, and made use of an induction-current so weak that it did not generally cause pain. He thus produced at one spot on the skin a sensation of pain, at another pressure, at a third cold, and at a fourth heat. These spots were distinctly locslised, and never superposed on one another. $\mathrm{He}$ gave special attention to the spots from which sensations of temperature were to be obtained. These he studied by means of a small metal tube drawn out to a conical point (Fig. III, below), and so arranged that a current of water could be kept flowing through it, thus enabling the observer to maintain the point at an epproximately constant temperature. Using this instrument, he investigated various parts of the skin, and mapped out the heat-spots and cold-spots in several regions. Further, he applied the crucial test : a heat-spot and a cold-spot hoving been found, the warmed point was applied to both, then the cold. No sensation followed the application of the warmed

\footnotetext{
' See "References to Literature" at the end.
} 
point to the cold-spot, or the cold point to the heat-spot; thus showing the complete differentiation of these temperature-organs.

Where the epidermis is thicker, he found that the stimulus must be stronger to get the desired reaction. This suggests that the so-called spots may only be the more superficial portions of the nerve-bearing layer of the skin, which is in reality all sensitive. That this is not the case, is shown by the fact that the stimulus may be applied to a neutral spot for an unlimited time, without giving rise to a thermal sensation. The general bearing of these results on the current theories is kept in view thronghout the paper. Blix, therefore, concluded that we have separate nerves for heat and cold, and that these have distinct terminations in the skin, which can be demonstrated.

Somewhat after the appearance of this paper by Blix, A. Goldscheider (2) published the results of a very important series of experiments.' He had been for some time stadying the specific energies of nerves, and in this connexion was led to investigate the sensations of temperature. For detecting the cold-spots he used either fine brushes dipped in ether or capillary tubes filled with the same. For locating both the heat-spots and the cold-spots he used small brass tubes brought to a conical point at one end and closed by a rubber-stopper at the other; these could be heated or cooled as was desired. To exactly mark the spots when found, he used a thermasthesiograph, by means of which a brush wet with Indian ink could be brought down quite exactly on the spot which had been previously stimulated. I regret, however, that he has given no account of precisely how he travelled over the skin with this apparatus, and thus developed his maps. Thus working, he found that temperature-sensations were roused only at definite spots. His maps show them as very much more abundant than either Blix or I found them.

As a rule the cold-spots are most abundent where the skin is most sensitive to cold, but what Goldscheider calls first-class spots, i.e., those which react strongly on moderate stimulation, may often be quite few in number, where the spots of all grades are numerous.

These spots are not alike on the symmetrical parts of the same individual, nor are they alike on the corresponding parts of diffe-

1 At this point explunation becomes unavoidable. I first learnel of (ioldscheider's work on this subject, through Nature for January 15th, 1885, which contained an abstract of a report made to the Physiological Society of Berlin on December 12th, 1884, by Prof. Eulenberg. In this abstract, mention is made of the work of both Blix and Goldscheider, but no mention of the place of publication. This was first discovered on Mfarch 13th, 1885, and on the following day I was able to consult the paper at the office of the Surgeon-General at Washington. At another point I shall state how much of my investigation is strictly independent, and how nuch is imitation of the work of the above authors. The mention of these dates, however, appeared to me necessary to prevent any misapprehension of the relation in which the various investigations stand to one another. 
rent individuals. What has been said for the cold-spots holds true also for the heat-spots. These latter are on the whole less abundant than the former, and tend somewhat to occupy the spaces from which the former are absent. There are certain spots which are roused only by excessive temperatures. Goldscheider notes also that a spot often stimulated loses its sensibility, apparently becoming exhrusted, for it does not react well until a more or less long period of rest has been allowed. When a heat-spot is overheated, it sometimes happens that a hyperæsthesia is produced, so that even pressure from a perfectly neutral body gives rise to a sensation of heat. He calls attention to the often observed fact that the tactile and thermal sensibilities in different parts of the body do not vary uniformly, and he points out that the discriminative sensibility when measured on two thermal spots is, as a rale, much finer than when measured in the ordinary way, and that this discrimination is finer the more intense the stimulus. In certain parts, as, for instance, those in which it is tinest, discrimination for tactile-sensations surpasses that for temperaturesensations.

These sensations of temperature can be roused by mechanical and electrical stimulation as well as thermal. In both cases the cold-spots are more easily discriminated than the heat-spots.

By sending a strong electrical current through the arm and parts of the hand and thus stimulating certain nerve-trunks, Goldscheider is able to get peripheral sensations of temperature; here, too, the sensations of cold tend to predominate. He finds these spots insensitive to pain or contact. A needle may bo plunged into them, or excessive temperatures applied without causing any feelings of discomfort.

Goldscheider also mentions the commonly observed persistence of sensations after the removal of the stimulus.

In sketching a general theory of temperature-sensations, Goldscheider brings a certain amount of evidence against the views of Hering (15). This latter investigator, relying mainly on the fact that water of the same temperature may feel cold or warm according as the hand is brought into it from a warmer or a colder vessel, concluded that, when the susceptibility of the thermal apparatus is decreased from one kind of stimulus, e.g., heat, it is increased for the other, e.g., cold, and vice versa. The experiment which Goldscheider records is this : If one hand be put into a vessel of water at $40^{\circ} \mathrm{C}$. and kept there for ten seconds, and if then both this hand and the one which during the meantime has been at the room-temperature be put into cold water, the warmed hand will feel the cold less distinctly than the one which has been kept in the air of the room. In going from a cold vessel to a hot one, heat is in the same way less distinctly felt by the hand which has been immersed. If, now, the view of Hering were correct, that the exhaustion for one stimulus was correlated with an increased sensitiveness to the other, we should expect the 
immersed hand to feel the change of temperature more acutely than the other; but this, we have seen, it does not do. Goldscheider therefore inclines to the older view of Weber.

Goldscheider's paper is further continued by an interesting discussion of the other sensations of the skin-pressure, pain and tickling; bat with those we are not at present concerned.

In a communication to the Physiological Bociety at Berlin (Dec. 15th, 1884), Prof. Ealenberg (3) states that he has been able, in the main, to corroborate the results of Blix and Goldscheider, but did not succeed in getting temperature-sensetions by mechanical stimulation. In Eulenberg's peper, chemical stimulation is spoken of as heving given positive results in Goldscheider's hands. As no mention is made of chemical stimulation in any of the published papers of Goldscheider which I have seen, I am inclined to think this statement erroneous.

The most recent paper is a note by Goldscheider (4) in which he reaches the conclusion that the temperature-nerves often radiate from centres, and that these centres often coincide with the hair-follicles.

\section{Experimental.}

As the work which hed been in progress before the receipt of Blix's peper involved the use of metel points at the temperature of the room, it naturally followed that the cold-spots were alone noticed. The moment attention was directed to the hest-spots their existence was easily demonstrated.

My first endeavour was to make an accurate map of these spots on some portion of the skin. Maps had been made long before, but they had been quite rough, and hence it was deemed worth while to repest the operation. For this purpose, the epparatus which had been previously in use was, with some slight modificetions, employed. This machine was devised by Prof. Stanley Hall, and will be described in a forthcoming paper, under the name of the " Kinesimeter". The description about to be given is intended to make clear the use of this instrument in this investigation alone.

The essential part is a rectangular brass table $T$ (Fig. I.), 36 $\times 33.5 \mathrm{cms}$. and $26.5 \mathrm{cms}$. high, supported on four legs. In the middle of this is a rectangular opening $25 \times 5 \mathrm{cms}$.; over this runs the car $R$, the wheels of which fit into grooves on either side of the opening. It can thus be rolled from one end of the opening to the other. At the ends of the opening are seen the grooved wheels $\mathrm{P}^{\prime}$ and $\mathrm{P}^{\prime}$, about which passes the endless cord $\mathrm{N} N$. This cord can be clamped to the side of the car, Bo that when the wheels are put in motion the car is moved $\mathrm{P}^{*}$ is geared with $\mathrm{P}$ so that the motion of $P$ is transmitted to it; in this way, by putting my finger on $\mathrm{P}$ and slowly turning it, a slow motion can be given to the car. 
Fia. I.

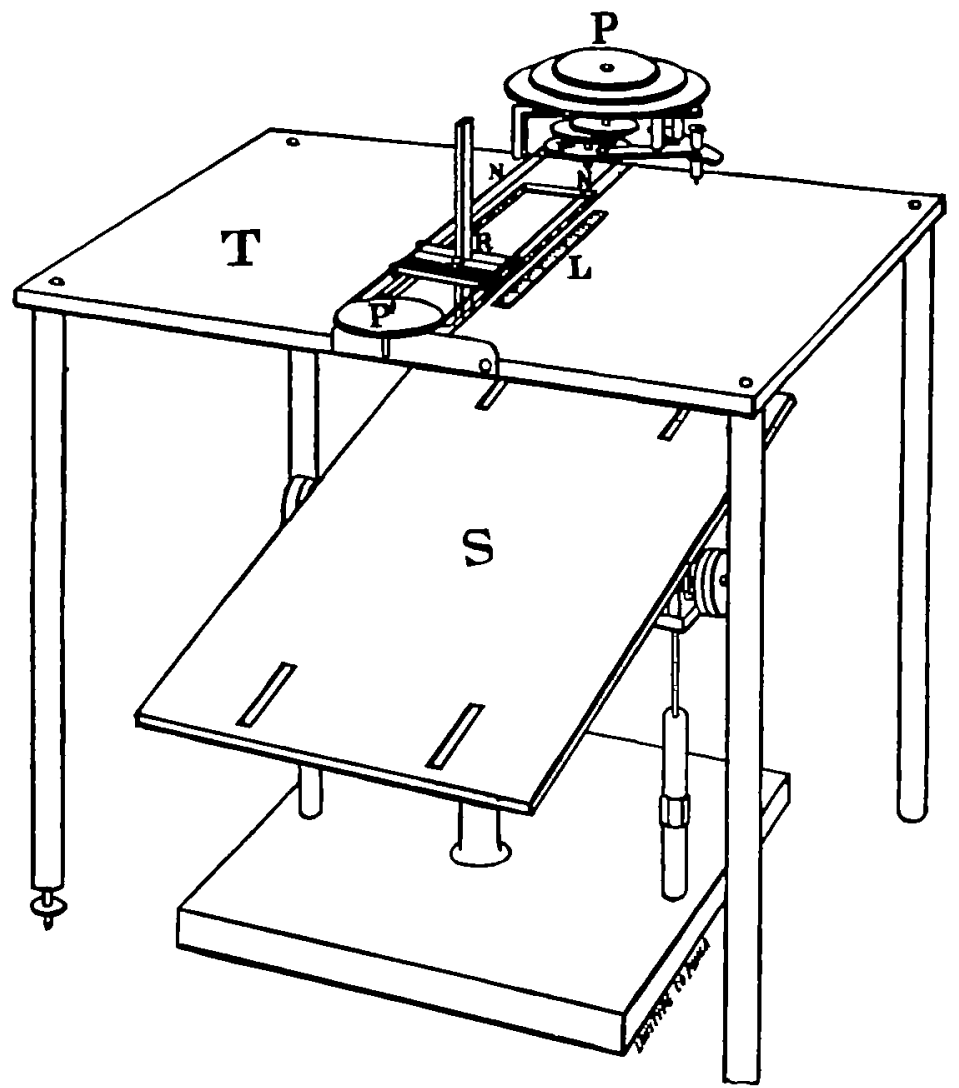

Fia. I.-The Kinesimeter (size s the original). T, Table; $R$, Car; N N, End. less cord ; P, P', P*, Groored wheels ; L Scale ; 8, Adjustible stpport.

The car itself (Fig. II.) hes the following construction. It consists of a square brass frame, $6 \times 6 \mathrm{cms}$., supported on four wheels. Joining the two sides of the frame are two cross-pieces $\mathbf{K}, \mathrm{K}^{\prime}$, having between them a space $1 \mathrm{~cm}$. wide. Within this space, and sliding by grooves along the cross-pieces $K, K^{\prime}$ is a cubical block of brass (not shown in the figure), which can thas be moved from one side of the car to the other through a distance of $4 \mathrm{cms}$. The upper side of $\mathrm{K}$ is marked off into millimetres, and the sliding block hess on it an index; by this means the position of the block can be exactly determined. By means of the screw $V$, the grooves in $K^{\prime}$ can be narrowed and the cubical block thus clamped in any position desired. Through the centre 


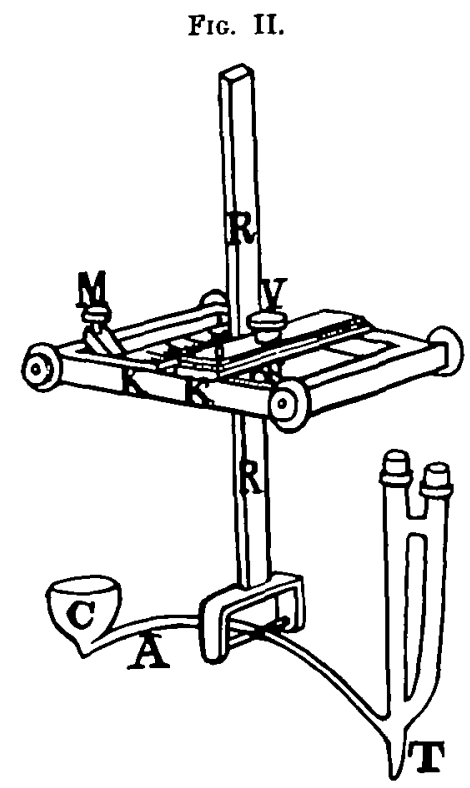

Fia. II.-Car (size b). R R, Adjustible rod ; A, Stringing arm ; C, Connterpoise cap; T, Hollow tabe (rubber tubing and flasks for keeping a continuous stream of water flowing through the tabe-not shown). N, Clamping screw to hold $R R$ in position; $K$, Cross piece with scale; $K^{\prime}$, Cross-piece, the groove of which can be narrowed; $v$, Clamping screw by which the FIG. III.

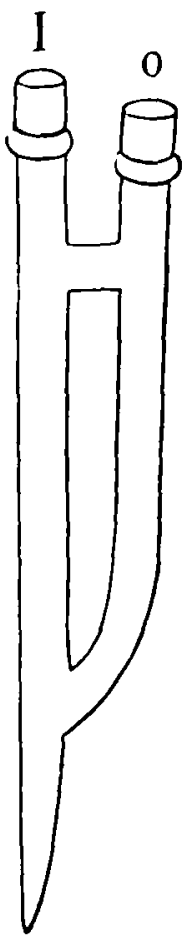
narrowing is effected; M, Clamp for fastening the endless cord to the car.

FIa. III.-Hollow pointed tube (actual size). I, Inflow; O, Ontflow (after Blix).

of the block runs the vertical rod $R \mathrm{R}, 10 \mathrm{cms}$. long, and rectangular in cross-section. This rod can be moved up and down, and fixed at any height by the clamping screw $\mathrm{N}$ (partly shown in the figure). The lower end of the rod bears the curved arm A, $8 \mathrm{cms}$. long, which swings vertically. At one end is the cup for holding a counterpoise weight; at the other the pointed tube is soldered (Fig. ILI.).

In Fig. I. is to be seen the support S. This is a heavy brass platform, the height and inclination of which can be adjusted within wide limits: when experimenting, a wooden trough was lashed to the top of this plate $S$, and in this trough the limb, supported at the sides by soft cloths, rested. Thus slight movements of the limb were prevented, and the whole plate could then be raised to the requisite height, and levelled for the experiment.

It remains to describe the device for applying the thermal stimulus to the skin. This was copied, in the later work, directly 
from Blix. A German silver tnbe (Fig. III.) was made in a way which is plain from the figure. Water of the requisite temperatare was allowed to flow through it, entering by the straight limb, and by this means any temperature could be maintained throughout the experiment. The point of this tabe which is applied to the skin, is $0.9 \mathrm{~mm}$. in diameter and rounded.

The part to be examined having been adjusted on the platform $\mathrm{S}$ as described (Fig. I.), the car was moved along until the point of the tabe was brought to rest on the desired spot. Then, supposing the portion of skin to be examined to be $2 \times 3 \mathrm{cms}$., by means of the gearing above described the car was made to move over the skin in a straight line and at a slow and uniform rate; the point pressing down with a weight of about $10 \mathrm{grms}$. The distance of $3 \mathrm{cms}$. having been thus traversed, the point is raised and the car rolled back to the place from which it started. Now by means of the block which carries the rod R R (Fig. II.) the point is moved $1 \mathrm{~mm}$. laterally, and the same thing repeated. Thus, in mapping out a space $2 \times 3$ cms., the car is drawn 21 times over the skin, making 21 parallel lines or practically tonching every bit of skin within the area. The fact that the point is $9 \mathrm{~mm}$. in diameter and is moved $1 \mathrm{~mm}$. each time, is not inconsistent with the above statement, for the sinking-in of the skin under the point brings practically a millimetre of surface in contact with the point on each tip.

For the purpose of making it possible to continue such observations for a number of days, the hand or other part of the body was marked. To do this a point was located in the back of the hand, for instance, by very careful measurements which could be repeated at any time. In a line at right angles to the long axis of the hand, another point was marked; then in a line at right angles to the line joining these two parts, a third point was placed a few centimetres distally.

Starting from the first-mentioned point, a series of very fine dots was placed along the transverse line at each millimetre. There was thus formed a line of 21 dots along the distance of 2 cms.

The hand was adjusted so that the lines drawn by the thermal point coincided with, or were parallel to, the line at right angles to this row of dots; by means of this device it was possible to srrest an experiment at any time, and take it up again from the exact point at which it had been stopped.

The marking the skin was done with a fine brush dipped in an indelible ink. The permanency of this marking material was its main recommendation; st the same time, it may not be out of place to draw attention to the fact that the slight inflammation cansed by the silver nitrate renders it unsuitable for marking the temperature-spots themselves.

The position of the spots at which heat or cold was felt, was recorded in the following way. On the car was a fine index 
which moved over the millimetre scale L (Fig. I.) as the car was drawn along. The index moved $1 \mathrm{~mm}$. for each $\mathrm{mm}$, of skin over which the point passed, so that, if the position of the index was observed at the start, the distance through which the point had moved on the surface could at any time be readily found. Fifths of a millimetre could be read on the scale, so that the position of the point could be accurately recorded. In practice then the position of the inder was noted when the point was on one of the dots on the hand. As the car moved on and a spot at which the temperature was felt was crossed, the person examined called " hot" or "cold" and the experimenter noted the position of the index. After the experiment, the positions of the spots were all calculated from these notes and recorded on paper raled in squares on which $1 \mathrm{~mm}$. was represented by $5 \mathrm{mms}$., thus enlarging the area twenty-five times. By this means, the small differences in the positions of spots could be recorded without confusion. The maps to be presented were made in this way, and then reduced to their true size, the points occurring within $\cdot 5$ min. being in these meps united into a single point.

There is of course the possible source of error that, where the surface is rough, $1 \mathrm{~mm}$. on the scale will not represent $1 \mathrm{~mm}$. on the skin. This has been attended to, and though it prevents the use of this method of experiment on certain parts, it does not become of any importance in the maps given.

There is another error which should be noted. The points being $9 \mathrm{~mm}$. wide, the lateral position of a spot is in doubt by $.45 \mathrm{~mm}$. All the spots are put down in the middle of the path of the point and are thus so far inexact. The relations of the spots are, I think, even under these conditions, pretty fairly represented. A number of preliminary experiments were made to see if any important variation was caused by varying the direction in which the point was drawn: the results were found the seme, whether the motion was up or down the limb or transversely, so that in the later experiments it was always drawn in one direction only. There is a slight variation caused by the movement of the skin itself under the point, especially at those places where the skin is loose; but where the movement is always in the same direction, this disturbing factor is reduced to zero.

Two carefully constructed maps are given (Figs. IV. and V.) for the left and right hands of the same individual, the parts being symmetrical. In this case the cold-spots are marked with dots and the heat-spots with circles; the difference in size indicates a difference in the intensity and regularity with which the sensation could be obtained from the different spots, the smaller spots being less sensitive.

In this work the temperature of the point used for finding the spots at which cold was felt, was about $15^{\circ} \mathrm{C}$, , while that for the heat-spots was about $50^{\circ} \mathrm{C}$. In the study of the spots on other parts of the skin, the metal tube of Blix was often held in the 
hand and thus moved about, this method answering for certain work very well. The other apparatus used will be described further on.

Fig. IV.

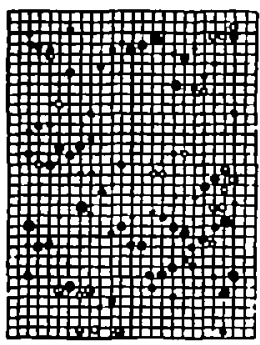

Fia. V.

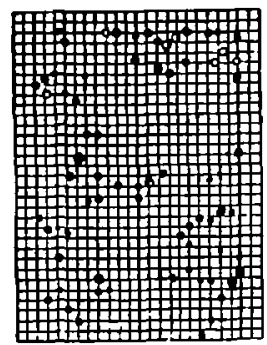

FiG. IV. - Map of the heat-spots and cold-spots on the back of the left hand. Extent, $2 \times 3 \mathrm{cms}$. Dots indicate cold; circles, heat; the larger ones represent the spots which give a strong reaction; the smaller, those which give a weak one. The top of the map is peripheral, the bottom central. The right side is the radial; the left the alnar.

FIa. V. - Similar map for the symmetrical portion of the right hand of the same individual. In this case, of course, the left side is the radial, and the right the ulnar.

In the statement of results it will be necessary to give them in chronological order to show how far they were independent. When first experimenting, a cold brass point, $1.5 \mathrm{mms}$. in diameter, was the only instrument used. With this I had found that cold was felt in spots, some spots giving an intense sensation, others a weak one; that the skin between these spots was not sensitive to cold; that the points were differently distributed in different parts of the same individual, and in similar parts of different individuals; that they were very small-as shown by the fact that unless a spot was carefully marked it could not be easily found again, for passing the point even very close to it did not rouse a sensation, as a rule; that they were permanent-once having been found they always could be found again; that they were easily exhausted-this being shown by the fact that, when the metal point was drawn down the arm and a certain number of points were observed, if it was again drawn down immediately, the number noticed on the second trip was almost always less than on the tirst, but if some minutes were allowed to elapse between the two trips, then the second result was, as a rale, like the first.

When I had gone thus far, Blix's paper was received. Blix (1), besides noting all the points above mentioned, found similar spots for heat, and found that what was true of the cold-spots was true of the heat-spots also, so far as their arrangement and distribution were concerned. He noticed also that the arrangement on symmetrical parts was not symmetrical ; that the rela- 
tive abundance of the two sorts of spots varied; that the heat-spots were rather less numerous; and that the two kinds were always distinct; further, he succeeded in getting them to react not only to thermal but also to electrical stimulation.

It was a simple matter to confirm Blix's observations on the heat-spots, and also his other observations on the temperataresense. For this purpose the modification of the Kinesimeter already described was ased. With regard to electrical stimulation there is something. more to be seid. Using unipolar stimnlation, with a pin for the small electrode, the sensation of cold came out very plainly at certain spots, while the sensation of heat was by no means so clear, as it seemed to me, and tended strongly to go over into burning pain which was almost unbearable. There were also other spots at which the electrode caused a burning pain from the first. Wishing to try the effects of altering the temperature of the electrode, I fastened one wire of the secondary coil to my hollow tube (Fig. III), and, using that, was thus enabled to have my electrode at any desired temperature. The experiment was planned as follows. A heat-spot and a coldspot were marked, then the electrode was cooled to $15^{c} \mathrm{C}$., and by it a weak current was sent through the spots. The sensations of heat and cold followed, as was expected. The temperature was then raised to about $30^{\circ} \mathrm{C}$., and again the current was applied. A sensation of heat was obtained at the proper point, but none of cold. So when the temperature was raised higher, the application of the current to the cold-spot gave no thermal sensation at all. Just what the meaning of this curious reaction is, $I$ am not prepared to say; but my experiments on this sabject are very concordant. These observations, taken in connexion with the fact that it is not very easy to get a good clear sensation of heat by electrical stimulation, indicate that further work is wanted here.

After the observations of Blix were thus corroborated, I continued the work in hopes of being able still to add something to the information already collected.

The investigation has proceeded on the assumption that these organs for heat and cold were in the skin. This idea is supported by the fact that a localised spot sensitive to temperature moves about as the skin is moved, and, when the skin is raised, comes up with it. If then the organs are in the skin, it should be possible to cut them out and examine them histologically.

A cold-spot and a hest-spot were localised on my own skin, and then cut out for me by Dr. Councilman. The bits of skin, about $3 \mathrm{mms}$. in diameter and the same in thickness, were treated by the gold chloride and formic acid method of Ranvier, hardened in alcohol, cut into serial sections perpendicular to the surface of the skin, and mounted in glycerine. For sectioning and mounting these specimens, I am indebted to Mr. H. F. Nachtrieb.

They had been marked with small dots of indelible ink, and the 
sections showed beneath the marking a slight inflammation. No difference could be made out between the spot at which cold had been felt and that at which heat was observed. There were numerous nerves beneath these spots, but they were almost as numerous in neighbouring parts. The result of the histological investigation then is so far completely negative. The cold-spot, it should be added, was taken from the middle of the lower leg on the anterior surface, while the heat-spot came from the middle of the volar surface of the forearm.

Thinking from this that the organs for the sensations of heat and cold might be quite independent of the papillary layer, I examined scars both on myself and others about the Laboratory. I also took the opportunity to examine some on patients at the Bay View Asylum. For this privilege I am indebted to Dr. Jones, the resident physician.

In the case of a woman with extensive burns (accident took place eighteen months ago), a large one on the arm, which had quite healed without much contraction, was very sensitive both to heat and cold. The point felt hotter on the scar than on the sound skin.

On the other arm the barn, in healing, had quite drawn together, and the bands of connective tissue beneath made the surface irregular. Here also both heat and cold were felt in spots, but were more intense on the superficial than on the deep parts of the scar.

In the case of a man who had two scars on his legs, consequent on deep incisions made some two years ago, the same sensitiveness was found, except for a line in the centre, about $3 \mathrm{mms}$. wide, where the scar was quite insensitive to contact, as well as to temperature. This line marked the place at which the incision had been made. For a little distance on either side of the line the point (either hot or cold) often gave rise to a pricking sensation. I later found the same pricking sensation from thermal stimulation of a large scar from a knife-wound on my own wrist made twenty years ago. Scars from boils are sensitive to temperature ; and one case examined, in which the skin had been mechanically torn away for a space about $1 \times 3 \mathrm{cms}$, and which was now healed, was exquisitely sensitive both to heat and cold.

It may further be added that the places on my own skin, from which the spots were removed, are now healed, 31 days having elapsed since excision, and are, so far as I can tell, as markedly sensitive to heat and cold respectively as they were before operation. I am aware that these observations do not accord with those of Weber (5). If I understand the statements of the facts as given by Weber, his experiments were made on wounds that had already healed, and therefore similar to those on which I have above reported. He found that a spatula at $8 \cdot 7^{\circ}-12 \cdot 5^{\circ} \mathrm{C}$. was not clearly distinguished from one at $45^{\circ}-50^{\circ} \mathrm{C}$., when applied to surfaces like burns on which the skin had been destroyed. 
The patients answered the question "hot" or "cold" as often wrongly as rightly, and occesionslly, for three successive times, called the hot spatula cold, while on the uninjured part of the skin they conld easily discriminate between them The temperatures which I used were $12^{\circ}-16^{\circ} \mathrm{C}$. for cold, and $50^{\circ}-55^{\circ} \mathrm{C}$. for heat; but the application was made with a point only $9 \mathrm{~mm}$. in diameter. The reason for the different results is, I think, this : When Weber rested his spatula on a thermally sensitive spot, the patient reacted correctly; but when it was between such spots, the patient had no thermal sensation and was forced to guess. That it is possible to find these thermally insensitive regions is pointed out by Blix and confirmed by my own experience. That they are sometimes quite large, even on sensitive parts, is plain from Figs. IV. and V. ; and furthermore I have noticed that on many scars the spots for the above temperatures were less abundent than on the sound skin. Finally I also found regions on the scars which were thermally insensitive, so that a spatula applied to them would have given the patient no idea of its temperature. This is to my mind the probable explanation of the contradiction here.

Later, Weber (5) did make some observations on a fresh wound, from which the skin hed been removed by a burn, and found it insensible to temperature-changes; but he did not study the regeneration of these nerves during the process of healing. Lussana (6) has lately examined the scar of a burn in the case of a woman, the injury having occurred thirty-five years before the examination. Here the injury was very deep, and the extent some $10 \times 12 \mathrm{cms}$. He states that in the region injured the temperature-sensibility is diminished, and concludes from this that this sensation is more delicate in the papillary layer than in the tissues beneath.

In this connexion it may be mentioned that, contrary to the explicit statement of Weber (5), I find the cosophagus, through its entire length, sensitive to temperature, both in myself and in a number of others. Some individuals do not distinguish clearly the temperature of a body in the cesophagus, but I have not found them as numerous as those that do. In one individual who was subject to certain dyspeptic attacks, accompanied by eructations, the temperature-sense in the cesophagus was apperently increased during the attacks. The tests were made with cold and hot water, at a temperature of $4^{\circ} \mathrm{C}$. and about $50^{\circ} \mathrm{C}$. The passage of the substance can, in my own case, be distinctly traced from one end of the cesophagus to the other, as a sensation - of heat or cold. On entering the stomach, a slight sensation is felt. but this is by no means so clear as that from the cesophagus.

The usual statement of the parts endowed with temperaturesensations does not include the conjunctiva, but this is reslly quite sensitive.

From all this, it follows that the end-organs for the sensation 
of temperature will have to be found in the cesophagus and conjunctiva, as well as in the places usually ramed.

The observations can be summed up as follows:-

The parts covered by skin have the temperature-organs in the skin. When the surfaces beneath the skin are tested, they are found insensitive to temperature.

The papillary layer is not necessary for temperature-sensations.

The nerves are generally regenerated in the healing of burns and other scars, except in certain places where the connective tissue is very dense.

To test the sensitiveness of these heat-spots to radiant energy; an apparatus was used, which was essentially like that described by Pollitzer (7). It consisted of a Pagaelin's thermocautery, which could be brought to bear over a hole in a thermally opaque diaphragm. The skin to be examined being brought benesth the hole, at a given instant the hole was uncovered and the heat fell on the skin beneath. The time which elapsed before the individual felt heat was recorded. In this case it was permissible to use the time ss the messure of sensitiveness, for within the region experimented on the thickness of the epidermis was practically constant. Moreover, testing the various distances at which the glowing point wes just perceived, gave similar results. By thermal stimulation cold, heat, and neutral spots were carefully located on the skin, and then marked. The patient was ignorant as to which was to be exposed. The glowing point was fixed at a constant height, the skin uncovered at a given signal, and the patient reacted to his first sensation. This was repeated three times for each spot in every experiment. The circle of skin exposed was $2 \mathrm{mms}$, in diameter. A typical series of results is given:

On J. V. D., March 10th, 1885.

$\begin{array}{clcc}\begin{array}{c}\text { Distanoe of point } \\ \text { in mms. }\end{array} & \text { Spot. } & \text { Timo in soconds. } & \text { Character of wonsation. } \\ 8 & \text { Heat- } & 3 & \text { Strung. } \\ 8 & \text { Cold- } & 25 & \text { Very slightegt. } \\ 8 & \text { Neutral } & 30 & \text { No sensation. } \\ 8 & \text { Nelltral } & 30 & \text { No sensation. } \\ 8 & \text { Heat- } & 3 & \text { Strong. } \\ 8 & \text { Cold- } & 16 & \text { Very slightest. } \\ 8 & \text { Cold- } & 40 & \text { No reaction. } \\ 8 & \text { Neutial } & 30 & \text { A mere breatl. } \\ 8 & \text { Heat. } & 16 & \text { Strong. }\end{array}$

It will be noticed here that sometimes a sensation of heat is recorded for other than heat-spots. In some cases it is, I think, simply an error of experiment, as in the sixth observation in the table above, where I presume a slight displacement of the hand exposed the edge of a heat-spot and thus gave a sensation. The very faint reaction sometimes obtained at points which gave no 
reaction on ordinary stimulation with a warmed point is, I think, due to spots sensitive to heat but brought into action at a comparatively high temperature only.

It is to be mentioned, however, that these faint sensations were never distinctly localised, while the strong sensations which followed the stimulations of a heat-spot were very sharply localised indeed.

An attempt was made to test the cold-spots by the aame method, but it did not succeed, it not being possible to get a low enough degree of temperature to give a good working-distance for the apparatus. It was of course noticed with these spots, as with the whole skin, that the thermal sensation when roused lasted some time after the removal of the stimulus, in some cases several minutes. This is often a disturbing element in certain experiments, for it is not always clear whether a given sensation comes from the spot at which the stimulus is acting, or from the spot at which it just acted. It is this fact which contributes largely to the continuity of the sensation of temperature when a stimulating body is drawn over the surface of the skin.

Having done this much on the subject, I received Goldscheider's (2) account of his own researches. The new points in his paper bearing on heat-sensation were - the number of spots found; their distribution ; mechanical stimulation ; their insensibility to pressure or pain ; temperature-sensations from stimulation of nervetrunks; and the increased discriminative sensibility on these spots.

In his maps the points are represented as much more numerous than they are in those presented by either Blix or myself. This is without doubt due to the fact that more intense stimuli, both for heat and cold, were used by Goldscheider than by either of us. His method was practically the same as that of Blix. Regarding the arrangement of these spots, both for temperature and pressure, his latest view is that they lie in lines radiating from centres, that these centres often coincide with the hairs in the hairy portions of the skin, and that in the hairless parts the arrangement is apparently the same. This statement 1 have not yet tested. He points out that these spots for both heat and cold can be roused by mechenical stimulation; a slight tapping over the surface where a temperature-spot is located giving rise to the sensations of heat or cold, the latter responding the more readily of the two. These experiments I have repeated, and the results are certainly very striking. Puncturing a temperaturespot also gives rise to temperature-sensations.

Moreover, he points out that these spots are insensible to pain or pressure. Repeating these experiments, I find complete analgesia in these spots, for a needle can be run into them without giving the slightest sensation of pain; but at the same time I have not been able to satisfy myself that I do not feel pressure. 
In certain cases Goldscheider succeeded in getting sensation of temperature by electrical stimulation of the nerve-trunks in the arm, back of the hand, \&c

These observations I have also repeated, using very strong electrical currents which gave almost continuous pain, as recommended by Goldscheider. By stimulating nerves in the back of the hand, I have succeeded in getting peripheral sensations of both heat and cold, the latter sensation being the more frequent. The sensation was localised in small areas in all the cases which I observed.

I am able also to corroborate his statement that the discriminative sensibility is much finer for temperature than for tactile sensations.

Since the receipt of Goldscheider's paper, I have been able to make one independent contribution to this subject, which, so far as I am aware, is new.

Dr. M. Warfield called my attention, a short time since, to the fact that in a certain operation on the eye by Dr. Russell Murdoch, cocaine having been used, the patient recognised the presence of the knife on the eye by a sensation of cold. By the courtesy of Dr. Murdoch, I was enabled to examine the eyes of several patients at the Baltimore Eye and Ear Hospital. When the eye in these cases was completely insensible to pain, and felt no contact whatever, cold and warm bodies were readily distinguished. This observation I have been able to repeat on my own eye. By means of 5 per cent. solution of muriate of cocaine the eye was rendered completely insensitive to pain or contact, but still readily felt heat and cold. ${ }^{1}$ Here we have the

1 At the end of a brief account of this action of cocaine, published in the Maryland Medical Journal, I requested observations on the temperature-sense by those who had occasion to use cocaine in the throat. Dr. John N. Mackenzie at once took up the matter, and has kindly furnisherl me the following summary of his resalts:-

"Sis patients were taken for experiment. The uvala and soft palate, and afterwards the nasal passages, were first bathed in a 4 per cent. solution of the muriate of cocaine. When anasthesia of the parts was complete, a ailver probe, which had been previously immersed in a mixture of ice and salt, was carried over the parts, rendered beforehand insensible to contact and pain, as tested in various ways. A distinct sensation of cold was in every instance complained of.

"The opposite extremities of the same probe were next hented over the argand burner of a lamp used for laryngoscopic purposes, and in its heaterl condition made to impinge upon various spots in the ansesthetised area. While absolutely no pain was felt by any of thase experimented upon, there was a marked unanimity of the answers in regrard to the sensation of heat. In three of the cases, the application of the heated probe left an eschar, and in one a pretty severe pharyngitis developed, yet at the time of application no pain was felt, though the temperature-sense remainet intact. None of the patients were aware of the purpose of the experiments or the previous preparation of the probe." 
temperature-sensations completely isolated from the other dermal sensations in a way which is now capable of easy repetition, and important as furnishing another argument for the independence of the thermal apparatus.

\section{Theoretical.}

The wider bearings of these results have been insisted on by both Blix and Goldscheider, but it may not be amiss to call attention to them here. The view of Weber (5), that we have but n single apparatus for both pressure and temperature, was mainly based on the fact that he did not succeed it separating the spots on the skin from which the two sensations were roused, and that a cold body felt heavier, a warm one lighter, than one at the temperature of the skin. But Szabadföldi (8), using disks of wood heated to $50^{\circ} \mathrm{C}$. and above, found that warm bodies were felt heavier than those not warmed, so that the force of the latter argument is much weakened.

Wunderli's (9) experiments showed that at obtuse points, as on the back, a touch with cotton wool and the approach of a warm body were sometimes confounded. If these experiments are taken to show a common origin for temperature and sensation of pressure, which by no means they do, then, as Blix points out, we must admit that heat, cold, and pressure of a certain grade are all identical, an idea which is absurd.

Against the view of Weber, there was, from the start, the objection that the temperature-sensations and discriminative sensibility did not vary pari passu, as might have been expected from his theory.

Further, there is the pathological evidence.

Brown-Síquard (10), and also other observers, have noticed that, in certain cases where the sensibility of the skin is abnormal, the pressure-sense and temperature-sense are not equally affected ; in fact, in some cases one may entirely disappear and the other remain intact. Evidence has also been brought forward to show that these two sensations pursue different paths in the cord.

Recently Adamkiewicz (11) has called attention to the fact that a sinapism has a different effect on temperature and tactile sensibility, for the sinapism causes no effects of transfer for temperature, while it does for the tactile sensations.

Herzen (12) has found that when the arm is made to fall "asleep" tactile sensibility is first abolished, then sensibility to pain; with the former the sensibility to cold disappears, while that for heat remains and does not disappear until the arm becomes insensitive to pain. Testing the rapidity of the transmission for the sensations of heat and cold, he found that the relative rapidity was as 3 to 2 . He adds the clinical fact of a woman who had no sensation of temperature from bodies below 
$27^{\circ} \mathrm{C}$. In this case the prost-nortem showed the posterior columus of the cord in an atrophied condition. He suggests then that the sensations of cold and pressure pass through the posterior columns, while heat and painful sensations are transmitted by the grey matter.

As besring directly on this question, the action of cocaine above described may be referred to.

Brücke (13) has called attention to the fact that in some cases we get different reflexes according as pressure or thermal stimulus is used.

The recent writers, Funke (14), Hering (15), and others, have assumed a special apparatus for the temperature-sensations on account of the distinct modality of the two sensations. So far as I know, the observations of Herzen (12), mentioned above, are the most important evidence for the duality of the temperaturesense itself.

Previously, there were various theories current as to how one apparatus could give rise to two sensations as clearly distinct as those of heat and cold.

Weber (5) put forward the view that it was the act of rising or falling in temperature which roused the thermal sensations. Vierordt (16) explained it as due to the direction in which heat was passing: when the current was directed from without inwards, we had the sensation of warmth; when from within outwards, the sensation of cold. Hering, relying mainly on his contrast- and exhaustion-experiments, considers that we have a single apparatus excitable in two ways, the two sensibilities standing in such relations to one another that, as one is exhausted, the other is reinforced. Goldscheider (12) rejects this notion of the double action of a thermal stimulus, on the ground of certain experiments mentioned in the first part of this paper. I have repeated these experiments and can fully confirm the results. We have then to look upon our temperature-sensations as mediated by two distinct sets of nerves, each set being quite independent of the other. The excitement of one set gives a characteristic sensation recognised as cold ; the other, a different sensation recognised as heat. The theory cannot be made to turn on the question as to whether the special nerve is gaining or losing heat; for, as these experiments show, the results can all be obtained with mechanical stimulation. As regards the after-action, on which so much stress has been laid, this, as Goldscheider remarks, is a purely nervous phenomenon quite independent of any changes of temperature.

The bearing of these observations on the measurement of the sensibility to temperature-differences is considerable, and there seems little doubt that the work designed to test the application of the psychophysical low to the skin-with its great averageerror-will have to be at least reviewed in the light of these new observations. As to their influence on the methods of testing 


\section{H. H. DONALDSON : ON THE TEMPERATURE-SENSE.}

the skin, it would be unsafe to predict. Eulenberg (3), in a very. recent paper, advances the idea that both for pressure and temperature we must still, as in the past, test on surfaces and not on points.

This investigation has brought to light some new facts and results, which have, without doubt, their greatest importance in controlling other lines of work. Some of these results, as I have endeavoured to show, were independently worked out in this Laboratory: but, in presenting a claim for independence, I hope that I have still made it clear that to Blix belongs the priority ; that Goldscheider's paper is very carefal and complete; and that $I$ am in a large measure indebted to both these observers.

My thanks are due to Prof. G. Stanley Hall for his aid and advice during this work. I also gladly take this opportanity to thank all those who have kindly placed themselves and their time at my disposal for experiment, and otherwise assisted me in this research.

\section{References to Literature.}

(1) Maynua Blix : Zoitscher f. Biol., Brl. xx., Heft 2 ; 1884.

(2) A. Goldscheider: Monatehefle f. pralt. Dermatol, Bd. iii, Nos 7,9, $10 ; 1884$.

(3) Eulenberg: Nature, Vol. xxxi., No. 7944; Jan. 15, 1885. Monatshefte f. prakt. Dormatol. Bd. iv., No. 1 ; 1885.

(4) A. Goldscheider : Monatshefto f. pralt. Dermatol, Bd. iv., No. 1 ; 1885.

(5) E. H. Weber: Wagner's Handrö̈rterbuch d. Physiol. Archiv. f. physiolog. Heilkunde; 1856.

(6) Lussana : Archiv. Ital. d. Biolog. Fasc. iii. ; 1883.

(7) S. Pollitzer : Jour. of Physiol., Vol. v., No. 3 ; 1884.

(8) Srabadföldi : Molesch. Untersuch. ix., 8. 631 ; 1865.

(9) Wunderli : Molesch. Untersuch vii., 8. $393 ; 1860$.

(10) Brown-Séquarl : Jour. do Physiol, Vol viii. ; 1863. Archives de Phy. siol, VoL i. ; 1868.

(11) Adamkiewicz : Berlin-Klin. Woehenechr., Nos. 18, 13 ; 1881.

(1z) Herzen : Revue Méd. d. l. Suisse rom. Vol. ii., p. 372 ; 1883.

(13) Brilcke : Vorlesungen ü. Physiol ; 1881.

(14) Funke : Hormant's Handb. dor Phyoiol., Bd. iii., Th. 2, s. 289.

(15) Hering : Hermann's Handb., Bd. iii., Th. 2, 8. 415.

(16) Vierordt : Grundriss d. Physiol., 5te Aufl., 355 ; 1877.

23rd Mareh, 1885. 